\title{
A RETROSPECTIVE ANALYSIS OF CAESAREAN SECTION IN A TEACHING HOSPITAL
}

\author{
Dattatraya Gopalghare1, Pranali Ghuge2, Swapnil Dhakane ${ }^{3}$
}

${ }_{1}^{1}$ Associate Professor, Department of Obstetrics and Gynaecology, MIMER Medical College, Talegaon Dabhade, Pune. 2Junior Resident, Department of Obstetrics and Gynaecology, MIMER Medical College, Talegaon Dabhade, Pune. 3Junior Resident, Department of Obstetrics and Gynaecology, MIMER Medical College, Talegaon Dabhade, Pune.

ABSTRACT

\section{BACKGROUND}

World Health Organisation states that every effort should be made to provide caesarean sections to women in need, rather than striving to achieve a specific rate. There are variations in caesarean section rates and its indications nationally and internationally.

Aims and Objective- To know caesarean section rate in our Institution. Analyse different indications of caesarean section. To find out proportion of different indications. To compare these proportions with other available studies. Analyse other associated factors like parity, gestational age, previous obstetric history, emergency or elective caesarean and anaesthesia given.

Study Setting- The study is carried out in the Department of Obstetrics and Gynaecology of MIMER Medical College, Talegaon Dabhade, Pune.

Study Design- It is an observational descriptive study.

\section{MATERIALS AND METHODS}

1. The data is collected from the hospital records to know total number of confinements during period of one year and ten months.

2. The total number of confinements, caesarean sections and their individual indications were noted.

3. Proportion of each indication was found out.

4. Other details like parity and gestational age, previous obstetric history and anaesthesia given were also studied.

Data Analysis and Statistical Tests- Rates and ratios are calculated from the observations.

\section{RESULTS}

Total 2240 delivered patient's records were studied retrospectively. Out of these, 500 had undergone caesarean section. The caesarean section rate was $22.3 \%$; $82.8 \%$ were done for emergency indications, $41.2 \%$ were primis, $33.2 \%$ had previous caesarean and $66.8 \%$ underwent a primary caesarean. Most common indication was cephalo-pelvic disproportion (34.8\%) followed by foetal distress (16.8\%) and meconium stained liquor (11.6\%). Only 5.4\% have undergone tubal ligation along with caesarean. In $99.6 \%$ cases, spinal anaesthesia was given.

\section{CONCLUSION}

In this study, the rate of caesarean section is $22.3 \%$. Here $41.2 \%$ patients were primiparous, $33.2 \%$ had previous caesarean and $66.8 \%$ underwent a primary caesarean. Commonest indications were cephalo-pelvic disproportion (34.8\%), foetal distress $(16.8 \%)$ and meconium stained liquor (11.6\%). Most of them (91.6\%) were full-term cases. Only 5.4\% cases have undergone tubal ligation along with the caesarean. For elective as well as emergency sections, spinal anaesthesia was given (99.6\%).

\section{KEYWORDS}

Caesarean Section Rate, Caesarean Section Indications.

HOW TO CITE THIS ARTICLE: Gopalghare D, Ghuge P, Dhakane S. A retrospective analysis of caesarean section in a teaching hospital.J. Evolution Med. Dent. Sci. 2017;6(29):2349-2352, DOI: 10.14260/Jemds/2017/506

\section{BACKGROUND}

Caesarean section is the removal of the foetus through an incision on the abdominal wall and the intact uterus. It is one of the most commonly performed surgical procedure globally. This surgical procedure has a very long and important history. There are many indications for caesarean section. Though the rate of caesarean section varies from place to place, nationally and internationally, there has been significant gradual increase in its rate over last few decades.

Financial or Other, Competing Interest: None.

Submission 01-03-2017, Peer Review 25-03-2017,

Acceptance 01-04-2017, Published 10-04-2017.

Corresponding Author:

Dr. Dattatraya Gopalghare,

LATIS Co. HSA Society, D4,

\#301, Talegaon-Chakan Road,

Tal-Maval, Pune.

E-mail: drgopalghare@yahoo.co.in

DOI: $10.14260 /$ jemds $/ 2017 / 506$

\section{(c) $($ ) $\$$}

Globally, there has been significant gradual decline in maternal morbidity and mortality as well as in neonatal morbidity and mortality over last few decades. There are many factors, which have contributed in this positive health development in our developing country. Amongst all these factors, caesarean section has played a great role.

We cannot only criticise the increase in its rate, but should also appreciate the significant improvement in maternal and neonatal outcome. There are many risks involved in caesarean section like postpartum haemorrhage and sepsis. At present with significant advancement in drugs used for controlling post-partum haemorrhage, easy availability of blood and blood products and plenty of antibiotics available at very less cost has really helped to reduce many of these complications. In current era of rapid scientific progress, we decided to know and analyse the different aspects about caesarean section in our Institution.

This study is carried out in the Department of Obstetrics and Gynaecology of a Medical College in rural India. 


\section{Aims and Objective}

1. To know caesarean section rate in our Institution.

2. Analyse different indications of caesarean section in our Institute.

3. To find out proportion of different indications of caesarean section.

4. Analyse other factors like parity, gestational age, previous obstetric history and type of anaesthesia given.

\section{Study Design}

It is an observational descriptive study.

\section{MATERIALS AND METHODS}

1. The data is collected from the hospital records of sequential 500 caesarean sections. Also the total number of confinements during period of one year and ten months were noted.

2. The total number of caesarean sections and their individual indications were noted.

3. Proportion of each indication was found out.

4. Other details like parity and gestational age, previous obstetric history, emergency or elective and anaesthesia given were also studied.

\section{RESULTS}

Total 2240 delivered patient's records were studied retrospectively. Many observations like parity, gestational age, mode of previous delivery, indication of caesarean section whether emergency or elective, if tubal ligation was done or not and type of anaesthesia given were recorded.

\begin{tabular}{|c|c|c|}
\hline Type of Delivery & Number & Percentage \\
\hline Vaginal Delivery & 1740 & $77.7 \%$ \\
\hline Caesarean Section & 0500 & $22.3 \%$ \\
\hline Total & 2240 & $100 \%$ \\
\hline \multicolumn{2}{|c|}{ Table 1. Mode of Delivery } \\
\hline
\end{tabular}

In this study, the rate of caesarean section was $22.3 \%$.

\section{Analysis of 500 Cases of Caesarean Section}

\begin{tabular}{|c|c|c|}
\hline Parity & Number & Percentage \\
\hline Primi & 206 & $41.2 \%$ \\
\hline Multi & 294 & $58.8 \%$ \\
\hline Total & $\mathbf{5 0 0}$ & $\mathbf{1 0 0} \%$ \\
\hline \multicolumn{2}{|c|}{ Table 2. Parity of Caesarean Section Patients } \\
\hline
\end{tabular}

Those who have undergone caesarean section, $58.8 \%$ were multiparous. Out of 294 multiparous patients, 166 had undergone previous caesarean section and 128 had previous vaginal delivery.

\begin{tabular}{|c|c|c|}
\hline Gestational Age & Number & Percentage \\
\hline 28 - 36 weeks & 041 & $08.2 \%$ \\
\hline 37 - 42 weeks & 458 & $91.6 \%$ \\
\hline$>42$ weeks & 001 & $00.2 \%$ \\
\hline Total & 500 & $100 \%$ \\
\hline
\end{tabular}

Out of 500 caesarean section cases, 458 were full-term patients.

\begin{tabular}{|c|c|c|}
\hline Previous CS & Number & Percentage \\
\hline Yes & 166 & $33.2 \%$ \\
\hline No & 334 & $66.8 \%$ \\
\hline Total & $\mathbf{5 0 0}$ & $\mathbf{1 0 0} \%$ \\
\hline \multicolumn{2}{|c|}{ Table 4. Mode of Previous Delivery } \\
\hline
\end{tabular}

Out of 500 caesarean section cases, 166 had previous caesarean delivery.

\begin{tabular}{|c|c|c|}
\hline Type of CS & Number & Percentage \\
\hline Emergency & 414 & $82.8 \%$ \\
\hline Elective & 086 & $17.2 \%$ \\
\hline Total & 500 & $100 \%$ \\
\hline \multicolumn{2}{|c|}{ Table 5. Emergency or Elective Caesarean Section } \\
\hline
\end{tabular}

Out of 500 caesarean cases, 414 were done for emergency indications.

\begin{tabular}{|c|c|c|}
\hline TL Done with CS & Number & Percentage \\
\hline Yes & 027 & $05.4 \%$ \\
\hline No & 473 & $94.6 \%$ \\
\hline Total & 500 & $100 \%$ \\
\hline \multicolumn{2}{|c|}{ Table 6. Tubal Ligation with Caesarean Section } \\
\hline
\end{tabular}

Only 5.4\% cases have undergone tubal ligation along with the caesarean section.

\begin{tabular}{|c|c|c|}
\hline Type of Anaesthesia & Number & Percentage \\
\hline Spinal & 498 & $99.6 \%$ \\
\hline General & 002 & $00.4 \%$ \\
\hline Total & $\mathbf{5 0 0}$ & $\mathbf{1 0 0 \%}$ \\
\hline Table 7.
\end{tabular}

Table 7. Type of Anaesthesia given for Caesarean Section

For elective as well as emergency caesarean sections, spinal anaesthesia was given.

\begin{tabular}{|c|c|c|}
\hline Indication of CS & Number & Percentage \\
\hline Cephalo-Pelvic Disproportion & 174 & $34.8 \%$ \\
\hline Foetal Distress & 084 & $16.8 \%$ \\
\hline Meconium Stained Liquor & 058 & $11.6 \%$ \\
\hline PROM & 034 & $06.8 \%$ \\
\hline Breech Presentation & 032 & $06.4 \%$ \\
\hline Non-progress of Labour & 030 & $06.0 \%$ \\
\hline Failed Induction & 021 & $04.2 \%$ \\
\hline $\begin{array}{l}\text { Previous LSCS and Scar } \\
\text { Tenderness }\end{array}$ & 015 & $03.0 \%$ \\
\hline Previous 2 LSCS & 014 & $02.8 \%$ \\
\hline Placenta Praevia & 007 & $01.4 \%$ \\
\hline Twins with First Non-Vertex & 006 & $01.2 \%$ \\
\hline Deep Transverse Arrest & 005 & $01.0 \%$ \\
\hline Malpresentations & 005 & $01.0 \%$ \\
\hline Occipito-Posterior Position & 004 & $00.8 \%$ \\
\hline Abruptio Placentae & 004 & $00.8 \%$ \\
\hline Contracted Pelvis & 003 & $00.6 \%$ \\
\hline Cord Prolapse & 002 & $00.4 \%$ \\
\hline Cervical Fibroid & 001 & $00.2 \%$ \\
\hline Previous CS and Didelphys Uterus & 001 & $00.2 \%$ \\
\hline Total & 500 & $100 \%$ \\
\hline
\end{tabular}




\section{DISCUSSION}

Total 2240 delivered patient's records were studied retrospectively. Out of these, 500 had undergone caesarean section. In this study, the rate of caesarean section was $22.3 \%$. Prashant Bade et al found caesarean section rate of $23.97 \%$ in similar type of setting. ${ }^{1}$ Hooja Nupur et al had rate of caesarean section of $26.6 \%$ in intrauterine foetal demise cases. $^{2}$ R. Subhashini et al observed that the rate of caesarean section has increased from $16.14 \%$ in 2004 to $25.66 \%$ in $2014 .^{3}$

Out of 500 caesarean cases, $414(82.8 \%)$ were done for emergency indications. In the study by R. Subhashini et al, $65.31 \%$ caesarean sections were done for emergency indications and $34.69 \%$ were done electively. ${ }^{3}$ Saima Rafique et al also found that $31.5 \%$ were elective and $68.5 \%$ emergency caesarean sections in their study. ${ }^{4}$

In our study, out of 500 patients those who have undergone caesarean section $58.8 \%$ were multiparous and $41.2 \%$ were primiparous. Out of 500 caesarean section cases, 166 (33.2\%) had previous caesarean delivery, 128 had previous vaginal delivery and $334(66.8 \%)$ underwent a primary caesarean section. Patel RV et al found that previous caesarean section contributed in $36.3 \%$ as the indication for repeat caesarean. ${ }^{5}$ Wanjari SA had caesarean rate of $37.8 \%$ and the most common indication for caesarean section in that study was repeat caesarean with one prior caesarean.6 Katke $\mathrm{RD}$ et al in a LSCS audit in a tertiary care centre in Mumbai got incidence of LSCS of $25.7 \%$ and previous LSCS was the leading indication in $35.2 \%$ cases. ${ }^{7}$ Yadav $S$ et al stated that $32.9 \%$ were elective and $67.1 \%$ had emergency LSCS. ${ }^{8}$ Mussart $\mathrm{N}$ et al found out at a teaching hospital at Faisalabad that $58 \%$ had emergency and $42 \%$ had elective caesarean section and $34 \%$ had previous caesarean section. ${ }^{9}$

Amongst the different indications of caesarean section, common once were cephalo-pelvic disproportion and foetal distress. Out of 500 caesarean sections, 174 (34.8\%) were diagnosed with cephalo-pelvic disproportion. Patel RV et al found CPD in $12.1 \%$ cases as the indication for repeat caesarean. ${ }^{5}$ Wanjari SA had caesarean rate of $37.8 \%$ and cephalo-pelvic disproportion was indication in $7.69 \%$ cases. $^{6}$ Katke RD et al in an LSCS audit found that only $4.64 \%$ cases were diagnosed with cephalo-pelvic disproportion. ${ }^{7}$ Mussart $\mathrm{N}$ et al found out that merely $2 \%$ cases of caesarean section had cephalo-pelvic disproportion. ${ }^{9}$ This shows that there is a lot of variation in percentage of cephalo-pelvic disproportion contributing to caesarean sections in different studies.

Foetal distress and meconium stained liquor contributed $84(16.8 \%)$ and $58(11.6 \%)$ respectively in current study. Saima Rafique et al noted that foetal distress contributed in $17.5 \%$ as an indication for caesarean sections in their study. ${ }^{4}$ Wanjari SA concluded that foetal distress/meconium stained liquor was an indication only in $9.36 \%$ cases. ${ }^{6}$ Katke RD et al found that $14.97 \%$ cases had foetal distress leading to caesarean section in their study. ${ }^{7}$ Yadav $S$ et al quoted foetal distress in $25.1 \%$ cases as an indication for LSCS. ${ }^{8}$ Mussart N et al found out that only in $9 \%$ cases foetal distress was an indication. ${ }^{9}$

Prolonged rupture of membranes was seen in 34 (6.8\%) cases in our study. Wanjari SA noted that in $7.31 \%$ of cases, PROM was the indication. ${ }^{6}$ Katke RD et al found that only $1.89 \%$ cases had PROM who underwent caesarean. ${ }^{7}$ Breech presentation was the indication for caesarean section in 32
(6.4\%) cases in our study. Wanjari SA stated that $4.21 \%$ cases had breech presentation who underwent caesarean. ${ }^{6}$ Katke $\mathrm{RD}$ et al found that $6.11 \%$ cases had various malpresentations leading to caesarean section. ${ }^{7}$ Mussart $\mathrm{N}$ et al found that in $6 \%$ cases malpresentation was an indication for caesarean section. ${ }^{9}$

Non-progress of labour was an indication in 30 (6.0\%) cases in current study. Saima Rafique et al found that in $14.3 \%$ cases, failure to progress led to caesarean section. ${ }^{4}$ Yadav $\mathrm{S}$ et al noted non-progress of labour in $6.1 \%$ of cases undergoing LSCS. ${ }^{8}$ Mussart $\mathrm{N}$ et al found that in $5 \%$ cases failure of progress of labour was the indication. ${ }^{9}$ In this study, $14(2.8 \%)$ cases had previous 2 caesarean sections leading to repeat caesarean in our study. Wanjari SA had 3.48\% cases with previous two caesarean sections leading to repeat caesarean. ${ }^{6}$ Katke RD et al had $10.54 \%$ cases with previous two caesareans leading to a repeat caesarean. ${ }^{7}$ Yadav $\mathrm{S}$ et al noted that $3.6 \%$ cases were with previous two sections undergoing LSCS. 8

In our study, failed induction was an indication for caesarean section in 21 (4.25\%) cases. Kaur S et al concluded in their study that post-datism was the commonest indication of induction of labour and caesarean section rate was $45.46 \%$ in induced cases. As caesarean section is more in induced labour, there is a need for judicious use of induction of labour. 10

Out of 500 caesarean section cases, 458 (91.6\%) were full term patients and only $41(8.2 \%)$ were preterm. Only $5.4 \%$ cases have undergone tubal ligation along with the caesarean section. For elective as well as emergency caesarean sections, spinal anaesthesia was given.

\section{CONCLUSION}

In this study, the caesarean section rate is $22.3 \%$. Indications of 500 caesarean sections were noted. Most of them (82.8\%) were done for emergency indications. Less than half (41.2\%) patients were primiparous. Significant number $(33.2 \%)$ had previous caesarean delivery and $66.8 \%$ underwent a primary caesarean. Most common indication was cephalo-pelvic disproportion (34.8\%). Foetal distress and meconium stained liquor contributed 84 (16.8\%) and 58 (11.6\%) respectively. Prolonged rupture of membranes was seen in $34(6.8 \%)$ cases. Breech presentation was the indication in $32(6.4 \%)$ cases. Non-progress was in $30(6.0 \%)$ cases; 14 (2.8\%) cases had previous 2 caesarean sections. Failed induction in 21 $(4.25 \%)$ cases. Out of 500 caesarean section cases, 458 $(91.6 \%)$ were full-term patients and only 41 (8.2\%) were preterm. Only $5.4 \%$ cases have undergone tubal ligation along with the caesarean section. For elective as well as emergency caesarean sections, spinal anaesthesia was given (99.6\%).

\section{REFERENCES}

[1] Bade P, Kendre V, Jadhav $\mathrm{Y}$, et al. An analysis of indications for caesarean section at Government medical college, Latur. Intern J Recent Trends Sci and Technol 2014;11(1):6-8.

[2] Nupur H. Indication of cesarean section in intrauterine fetal demise. Sch Acad J Biosci 2014;2(10):724-7.

[3] Subhashini R, Uma N. Changing trends in cesarean delivery. IAIM 2015;2(3):96-102. 
[4] Rafique S, e Raana G. Changing trends in cesarean section rate and indications. Pak J Surg 2012; 28(1):60-4.

[5] Patel RV, Gosalia EV, Deliwala KJ, et al. Indications and trends of cesarean birth delivery in the current practice scenario. Int $\mathrm{J}$ Reprod Contracept Obstet Gynecol 2014;3(3):575-80.

[6] Wanjari SA. Rising cesarean section rate: a matter of concern? Int J Reprod Contracept Obstet Gynecol 2014;3(3):728-31.

[7] Katke RD. LSCS audit in a tertiary care center in Mumbai: to study indications and risk factors in LSCS and it's effect on early peri-natal morbidity and mortality rate. Int J Reprod Contracept Obstet Gynecol 2014;3(4):963-8.
[8] Yadav S, Kaur S, Yadav SS, et al. Analysis of cesarean rate, indications and complications: review from medical college Ambala, Haryana, India. Int J Reprod Contracept Obstet Gynecol 2016;5(10):3326-9.

[9] Mussart N, Qureshi S, Roohi M. Lower segment cesarean section (LSCS): indications and complications at teahcing hospital, Faisalabad. Professional Med J 2013;20(6):916-23.

[10] Kaur S, Kawthalkar A. Induction of labour - the current trend in a tertiary care hospital. Panacea Journal of Medical Sciences 2015;5(2):85-6. 